\title{
Failed induction of labor (IOL): an overview regarding obstetric outcome and its significance in a health resource poor setting over a period of 11 months
}

\author{
Karthik Chandra Bassetty*, Reena Dutta Ahmed
}

Department of Obstetrics and Gynecology, Assam Medical College and Hospital, Dibrugarh, Assam, India

Received: 15 June 2017

Accepted: 08 July 2017

*Correspondence:

Dr. Karthik Chandra Bassetty,

E-mail: kcbassetty@gmail.com

Copyright: () the author(s), publisher and licensee Medip Academy. This is an open-access article distributed under the terms of the Creative Commons Attribution Non-Commercial License, which permits unrestricted non-commercial use, distribution, and reproduction in any medium, provided the original work is properly cited.

\begin{abstract}
Background: The aim of the study was to evaluate the indications and outcomes of failed induction in primigravidae in a tertiary care hospital located in a health resource poor setting.

Methods: We conducted a retrospective cross-sectional study on women admitted in the labor room and planned for induction of labor in Assam Medical College and Hospital, Dibrugarh from $1^{\text {st }}$ July 2016 to $31^{\text {st }}$ May 2017. Induction was considered successful if the patient delivered vaginally and failed if it ended up in Caesarean section.

Results: A total of 201 primigravida patients were selected for the study of which 135 patients delivered by CS and 66 patients by spontaneous vaginal delivery. The average induction-delivery interval was found to be 18.9 hours. Average weight of the babies was $2.9 \mathrm{~kg}$. The following factors are associated with increased rates of failed induction: Bishop's score less than 5, Gestational age $>41$ weeks, teenage and elderly primi, oligohydramnios, prelabour rupture of membranes (PROM), hypertensive disorders of pregnancy, induction-delivery interval greater than 24 hours, absence of a dating ultrasound done in $1^{\text {st }}$ trimester, meconium stained liquor, SGA and macrosomia babies. There has been a single maternal death due to rupture of uterus.

Conclusions: Most common indication of doing IOL is post-dated pregnancy ( $>40$ weeks of gestation). Majority of women $(66 \%)$ had no dating ultrasound with them hence they were induced based on last menstrual period which is unreliable in most women leading to failed IOL.IOL protocol i.e. when to repeat and how long to wait was purely the duty consultant's opinion in our study rather than following a protocol. IOL is an important obstetric procedure hence there is a dire need to develop a protocol for the same in our setup.
\end{abstract}

Keywords: Caesarean section, Cerviprime, Failed induction, Labor induction, Post-dated pregnancy

\section{INTRODUCTION}

Induction of labor (IOL) is the artificial initiation of labor before its spontaneous onset for the purpose of achieving a vaginal delivery. ${ }^{1,2}$ It is a common obstetric procedure. It is indicated when the benefits to the mother or fetus outweigh the benefits of continuing the pregnancy. ${ }^{1,2}$ The rate of IOL varies by location and institution. ${ }^{1,2}$ It is well established that labor has to be induced in approximately
$20 \%$ of pregnancies. ${ }^{3}$ However, induction fails in $20 \%$ of induced pregnancies. ${ }^{4}$ Well established risk factors for failed induction are bishop's score $<6$, nulliparity, gestational age $<41$ weeks, maternal age $>30$ years, pregnancy complicated by preeclampsia, premature rupture of membranes (PROM), isolated oligohydraminos, gestational diabetes, and hypertension. ${ }^{4-6}$ There are several methods for labor induction; however the preferred method is intra-cervical prostaglandin E2(PGE2-cerviprime). It induces or 
accelerates the maturation of cervix also known as cervical ripening and stimulating the myometrial activity. $^{7}$

\section{METHODS}

Based on the above considerations, we conducted a retrospective cross-sectional study choosing a specific study population comprising of only primigravida patients. In particular, we tested the success rate of induction of labor in patients with risk factors for failure such as nulliparity, maternal age (>30 years), unfavourable Bishop score and obstetric conditions (egPROM, prolonged draining, Rhesus negative mothers etc). A total of 201 primigravida patients attending the labor room from $1^{\text {st }}$ September to $31^{\text {st }}$ May 2017 for labor induction were included in the study. The inclusion criteria were as follows: singleton pregnancy, nulliparity, 37-42 week gestation, the absence of active labor, only drug used for induction is PGE2, live fetus with cephalic presentation, and no contraindication to vaginal delivery. The induction of labor was decided for the following indications: post-dated pregnancy $>40$ weeks of gestation, PROM (spontaneous labor not started after 24 hrs), isolated oligohydramnios, IUGR, prolonged draining (>18 hours), hypertensive disorders of pregnancy. The primary outcome measure was caesarean section (CS) rate and vaginal delivery. Secondary outcomes noted were the mean induction-delivery interval, Apgar score at 10 mins, complications to the mother during the process of IOL. Apgar score was evaluated between the two groups as neonatal outcome. Bishop score was assessed by digital examination of the cervix. Labor induction was carried out according to treating consultant on duty or the concerned Unit Chief. The fetal well-being was evaluated every 1 hour by intermittent auscultation. If the fetal heart rate was abnormal during intermittent auscultation, patient was further reassessed after a trial of left lateral position, oxygen supplementation, intravenous fluids. If the heart rate did not correct after $10 \mathrm{mins}$, artificial rupture of membranes (AROM) was done if feasible. Vaginal prostaglandin PGE2 gel $500 \mathrm{mcg}$ was inserted into the posterior fornix or intracervically. Depending on the favorability of the cervix and fetal status, repeat dose of PGE2 gel was given in 2 or 3 doses after 6 hours. Failure of induction was defined as no onset of labor $24 \mathrm{~h}$ following the initiation of induction of labor or onset of fetal distress detected by intermittent auscultation. Cesearean section was done if there was a failure to go into active labor or if fetal distress/maternal risk exceeded the induction process benefits. The patients were divided into two groups: Group A (CS) and Group B (vaginal delivery). The Ethical Committee of the college approved the study.

\section{RESULTS}

Of the 201 patients selected, 135 patients underwent a CS and 66 patients had a spontaneous vaginal delivery. The average induction-delivery interval was found to be 18.9 hours. Average weight of the babies was $2.9 \mathrm{~kg}$. The following factors are associated with increased rates of failed induction: Bishop's score less than 5, Gestational age $>41$ weeks, teenage and elderly primi, oligohydramnios, prelabour rupture of membranes (PROM), hypertensive disorders of pregnancy, inductiondelivery interval greater than 24 hours, absence of a dating ultrasound done in $1^{\text {st }}$ trimester, meconium stained liquor, Small For Gestational Age (SGA) and macrosomia babies.

Table 1: $P$ value and significance of various factors associated with failed induction of labor.

\begin{tabular}{|c|c|c|}
\hline Factor & P value & Significance \\
\hline Bishop's score $(<5)$ & $<0.0001$ & $\begin{array}{l}\text { Extremely } \\
\text { statiscally } \\
\text { significant }\end{array}$ \\
\hline $\begin{array}{l}\text { Gestational age }>41 \\
\text { weeks }\end{array}$ & $<0.0001$ & $\begin{array}{l}\text { Extremely } \\
\text { statiscally } \\
\text { significant }\end{array}$ \\
\hline $\begin{array}{l}\text { Extremes of age } \\
\text { (teenage and elderly) }\end{array}$ & 0.0301 & $\begin{array}{l}\text { Statiscally } \\
\text { significant }\end{array}$ \\
\hline Oligohydramnios & $<0.0001$ & $\begin{array}{l}\text { Extremely } \\
\text { significant }\end{array}$ \\
\hline Prolonged draining & 0.05 & $\begin{array}{l}\text { Not quite } \\
\text { statiscally } \\
\text { significant }\end{array}$ \\
\hline $\begin{array}{l}\text { Prelabour rupture of } \\
\text { membranes }\end{array}$ & $<0.0001$ & $\begin{array}{l}\text { Extremely } \\
\text { statiscally } \\
\text { significant }\end{array}$ \\
\hline $\begin{array}{l}\text { Gestational } \\
\text { hypertension }\end{array}$ & 0.0155 & $\begin{array}{l}\text { Statiscally } \\
\text { significant }\end{array}$ \\
\hline $\begin{array}{l}\text { Induction delivery } \\
\text { interval }<24 \text { hours }\end{array}$ & $<0.0001$ & $\begin{array}{l}\text { Extremely } \\
\text { statiscally } \\
\text { significant }\end{array}$ \\
\hline Rh negative pregnancy & 1 & $\begin{array}{l}\text { Not } \\
\text { statiscally } \\
\text { significant }\end{array}$ \\
\hline Dating USG & $<0.0001$ & $\begin{array}{l}\text { Extremely } \\
\text { statiscally } \\
\text { significant }\end{array}$ \\
\hline IUGR & 0.47 & $\begin{array}{l}\text { Not } \\
\text { statiscally } \\
\text { significant }\end{array}$ \\
\hline Hyperthyroidism & 1 & $\begin{array}{l}\text { Not } \\
\text { statiscally } \\
\text { significant }\end{array}$ \\
\hline $\begin{array}{l}\text { Number of cerviprime } \\
\text { doses }<2\end{array}$ & 0.067 & $\begin{array}{l}\text { Not quite } \\
\text { statiscally } \\
\text { significant }\end{array}$ \\
\hline $\begin{array}{l}\text { Number of cerviprime } \\
\text { doses }<1\end{array}$ & 0.067 & $\begin{array}{l}\text { Not quite } \\
\text { statiscally } \\
\text { significant }\end{array}$ \\
\hline $\begin{array}{l}\text { Meconium stained } \\
\text { liquor }\end{array}$ & $<0.0001$ & $\begin{array}{l}\text { Extremely } \\
\text { statiscally } \\
\text { significant }\end{array}$ \\
\hline $\begin{array}{l}\text { Extreme baby weight } \\
(<2 \mathrm{~kg}+>3.5 \mathrm{~kg})\end{array}$ & $<0.0001$ & $\begin{array}{l}\text { Extremely } \\
\text { statiscally } \\
\text { significant }\end{array}$ \\
\hline
\end{tabular}


Table 2: Delivery modality of mothers.

\begin{tabular}{|llll|} 
Group A & $(\mathrm{CS})=135$ babies & \multicolumn{2}{l}{$\begin{array}{l}\text { Group B (vaginal } \\
\text { delivery) }\end{array}$} \\
Male & Female & Male & Female \\
\hline 71 & 64 & 28 & 38 \\
\hline
\end{tabular}

There has been a single maternal death due to rupture of uterus. The patient was shifted to the ICU after the caesearan has been done, to save the mother as the baby expired before the patient was shifted to the operating room. Cause of rupture was attributed to a chance event. The most common reason for starting the induction of labor was post-dated pregnancies i.e once the expected date of delivery (EDD) was crossed even by a single day.

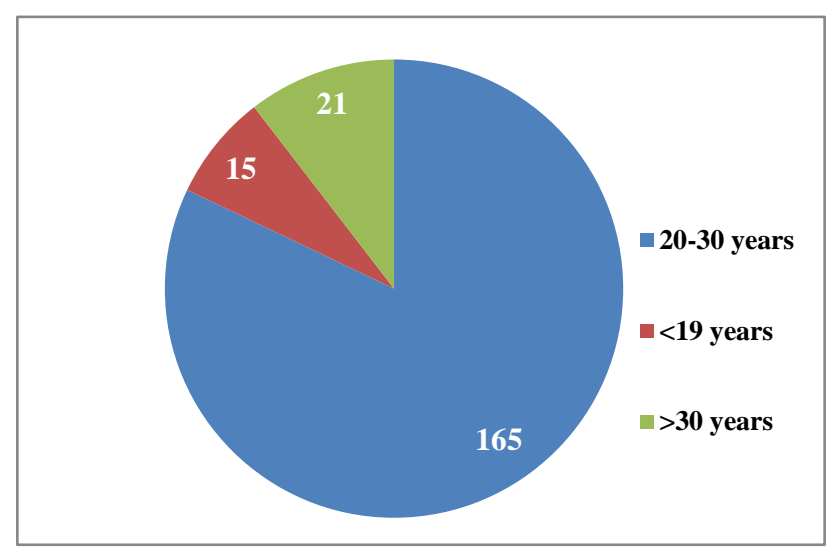

Figure 1: Age group of the patients.

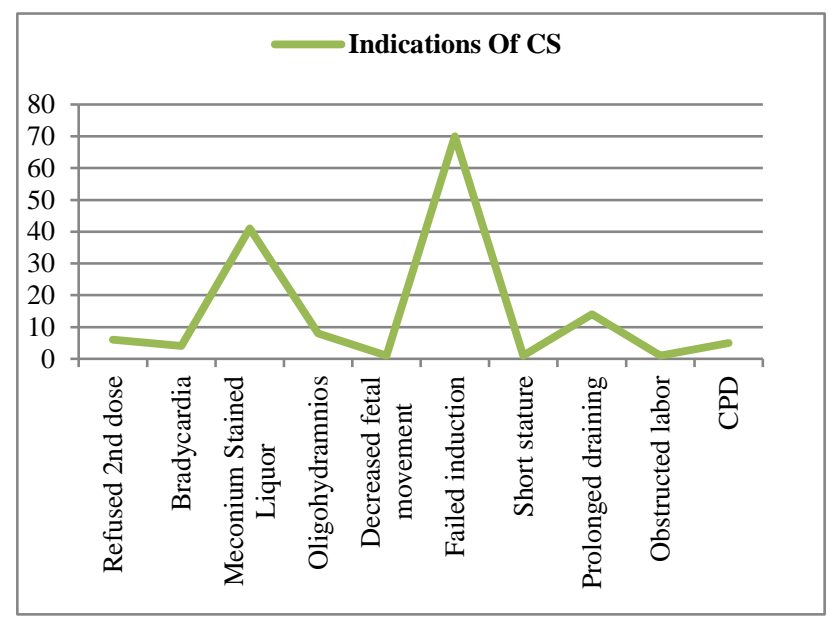

Figure 2: Indications of patients who were taken up for caserean section following induction of labor.

Most common cause of failed induction was the failure of labor to progress after 24 hours. The most common complication encountered was chorioamniotis. This was found to be associated with prolonged draining >24 hours.
Table 3: Outcomes of babies delivered in the study.

\begin{tabular}{|c|c|c|}
\hline Healthy babies & $\begin{array}{l}\text { Resuscitation } \\
\text { failure }\end{array}$ & Stillborn \\
\hline 199 & 1 & 1 \\
\hline
\end{tabular}

A single episode of massive intraoperative PPH was noted to occur in one patient attributed to multiple myoma undiagnosed prior to the CS. The patient underwent multiple episodes of dialysis due to acute kidney injury (AKI). Eventually after 6 dialysis sittings and 4 units blood transfusion she recovered.

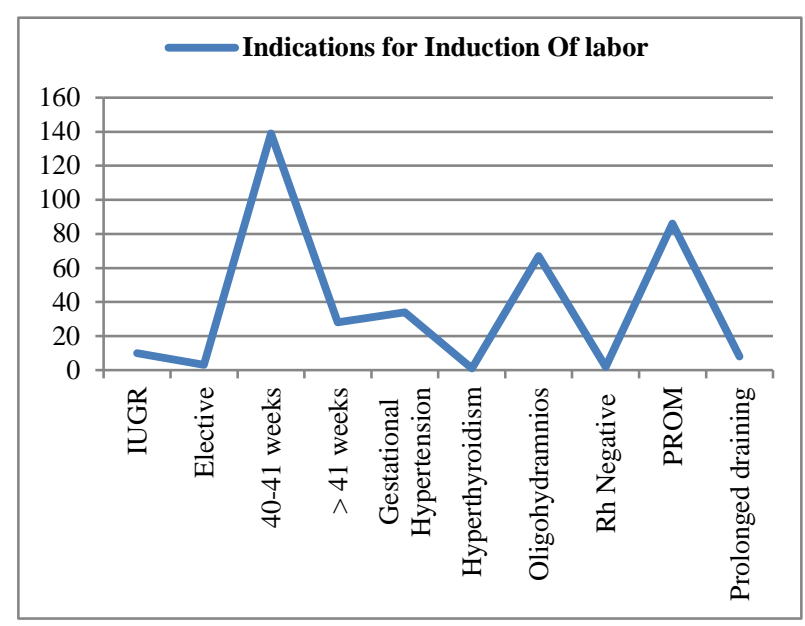

Figure 3: Factors for which induction of labor was done.

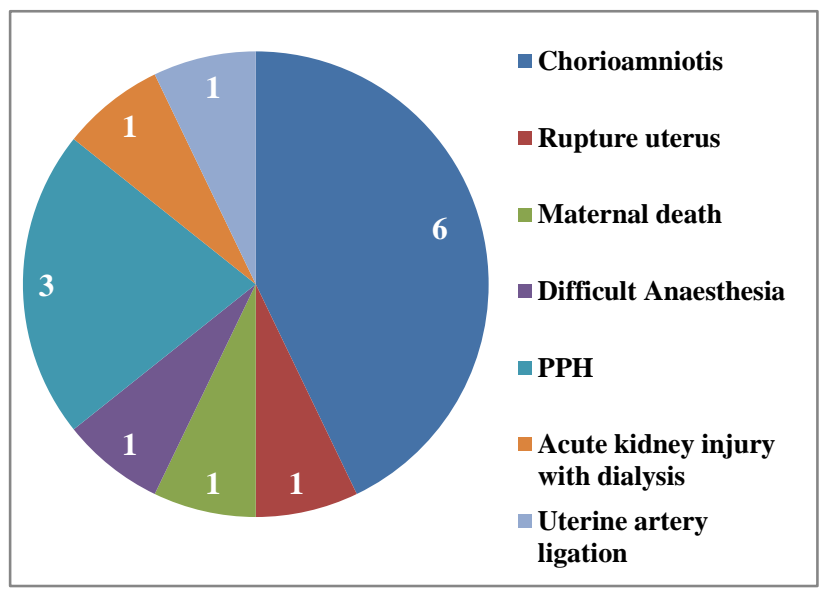

Figure 4: Complications associated with induction of labour in mother.

\section{DISCUSSION}

The study was initiated to study a clinical entity called "failed induction" in our clinical scenario where there is no fixed protocol for induction of labor (IOL). Lin and Rouse suggested a practical definition of failed IOL as the inability to achieve cervical dilatation $>4 \mathrm{~cm}$ after 12 $\pm 3 \mathrm{~h}$ of oxytocin administration. ${ }^{9}$ Nonetheless, a successful vaginal delivery is still considered by many 
doctors as the main IOL outcome, although it depends on many other factors interacting during labor which are not necessarily related to the induction process. The time interval between the $2^{\text {nd }}$ dose of PGE2 gel and the delivery process has not been quantified. Timely onset of labor and delivery is an important determinant of maternal and perinatal outcome. Post-term births are associated with higher rates of perinatal morbidity and mortality especially a risk of sudden death in utero than pregnancies delivered at term. ${ }^{10}$ Hence originates the practice of routine induction at or just after 40 weeks according to some consultants. The condition of cervix at the start of induction is an important predictor, with the modified Bishop score being a widely used scoring system. Induction of labor results in high failure rate if the cervix is not ripe. ${ }^{11,12}$ The most important element of the Bishop's score is dilatation. ${ }^{13-15} 6$ patients refused the second dose of PGE2 gel citing excessive labor pains. In a study done by Neelofur et al, women with failed induction were 2.9 times more at odds of having prolonged latent phase and 1.4 times more likely to have prolonged second stage. ${ }^{16}$ In present study we found the mean induction to delivery interval to be 18.9 hours. But the literature says induction of labor can be delayed up to 41 weeks if proper monitoring of fetal condition can be done. We have a paucity of monitoring devices for the fetus hence the threshold for withholding a LSCS against continued monitoring in our setup is very low.

Certain characteristics of the fetus predispose to induction failure. Higher birth weights have been found to increase the risk of failed induction and a lower rate of vaginal delivery. ${ }^{17,18}$ This is consistent with our study results where we found both the SGA and LGA fetus to significantly increase the rate of caesarean section.

This study shows the magnitude of association of different factors related to failed IOL. We have found a scarcity of studies regarding the protocol for induction of labor. There have been no studies regarding the same in our state of Assam. The limitations of the study are as follows: Ours is a retrospective study. Secondly absence of CEFM (continuous electronic fetal monitoring) makes monitoring of labor difficult. So, adhering to protocols is a better difficult proposal in our setup so procrastinating the case for a caesarean section is rarely done.

Merits of our study is that it provides a proper perspective of induction scenario in the North-East sector of India where medical resources are scarse. It also shows the importance of dating ultrasound in predicting the gestational age as gestational age derived from last menstrual period is not reliable.

\section{CONCLUSION}

IOL is a part and parcel of any obstetrician toolbox. Used properly it can decrease the rates of CS but improper IOL just because the women have crossed the expected date of delivery is a practice to be stopped since it increases the
CS rates and does not improve the fetal outcome rather leads to increased morbidity and even mortality for the mother.

\section{Recommendations}

Larger multicentre, prospective studies have to be done to have a better understanding of factors leading to failure of induction of labor. First trimester ultrasound is an important tool in diagnosis of term pregnancies. We recommend every pregnancy to be dated in first trimester in this era of diagnostic imaging and to decide on a common induction protocol after a thorough discussion with the hospital care policy. Improve the health care facilities in the primary health care system.

\section{ACKNOWLEDGMENTS}

Authors would like to thank the Medical Superintendent of Assam Medical College and hospital, Dibrugarh for his permission to do the study. Author also express gratitude to Miss Kalyani Vamsy Bassetty and Dr. Keerthy Chandra Bassetty for their patience and timely help in analysis of data.

Funding: No funding sources Conflict of interest: None declared

Ethical approval: The study was approved by the Institutional Ethics Committee

\section{REFERENCES}

1. SOGC Clinical practice guidelines; 2001. Available at http://old.sogc.org/clinical-practice-guidelines/

2. Tenore JL. Methods for cervical ripening and induction of labor. Am Fam Phys. 2003;67(10):2123-8.

3. Pandis G, Papageorghiou AT, Ramanathan VG, Thompson MO, Nicolaides KH. Preinduction sonographic measurement of cervical length in the prediction of successful induction of labor. Ultrasound Obstet Gynecol. 2001;18(6):623-8.

4. Gulmezoglu AM, Crowther CA, Middleton P. Induction of labour for improving birth outcomes for women at or beyond term. Cochrane Database Syst Rev. 2006;4.

5. Park KH, Hong JS, Ko JK.Comparitive study of induction of labor in nulliparous women with premature rupture of membranesat term compared to those with intact membranes: duration of labor and mode of delivery. J Obstet Gynecol Res. 2006;32:482-8.

6. Tucker Edmonds B, Fager C, Srinivas S. Predictors of casarean delivery for periviable neonates. Obstet Gynecol. 2011:118:49-56.

7. Xenakis EM, Piper JM, Field N, et al. Preeclampsia: is induction of labor more successful? Obstet Gynecol. 1997;89:600-3. 
8. Mozurkewich EL, Chilimigras JL, Berman DR. Methods of induction of labor: a systematic review, BMC Pregnancy Childbirth. 2011;27(11):84.

9. Lin MG, Rouse DJ. What is failed induction ? Clin Obstet Gynecol. 2006;49:585-593.

10. Caliskan E, Dilbaz S, Gelisen O, Dilbaz B,Ozturk N, Haberal A. Unsuccessful labor induction in women with unfavourable cervical scores: predictors and management. Aus NZ J Obstet Gynecol. 2004;44:562-7.

11. Park KH, Hong JS, Shin DM, Kang WS. Predictors of failed induction in parous women at term; role of previous obstetric history, digital examination and sonographic measurement of cervical length. J Ostet Gynaec Res. 2009;35:301-6.

12. Watson WJ, Stevens D, Welter S, Day D. Factors predicting successful labor induction. Obstet Gynecol. 1996:88:990-2.

13. Satin AJ, Leveno KJ, Sherman ML, McIntire DD. Factors affecting the dose response to oxytocin for induction stimulation. Am J Obstet Gynecol. 1992:166:1260-1.

14. Chandra S, Crane JMG, Hutchens D, Yg DC. Transvaginal ultrasound and digital examination in predicting successful labor induction. Obstet Gynecol. 2001:98:2-6.
15. Michelson KA, Carr DB, Easterling TR. The impact of duration of labor induction on caesarean rate. Am J Obstet Gynecol. 2008;199:299.el-4.

16. Khan NB, Ahmed I, Malik A, Sheikh L. Factors associated with failed induction of labour in a secondary care hospital. JPMA-Journal of the Pakistan Medical Association. 2012;62(1):6.

17. Vrouenraets FP, Roumen FJ, Dehing CJ, van den Akker ES, Arts MJ, Scheve EJ. Bishop score and risk of cesarean delivery after induction of labor in nulliparous women. Obstet Gynecol. 2005;105:6907.

18. Vahratian A, Zhang J, Troendle JF, Scisclone AC, Hoffman MK. Labor progression and risk of cesarean delivery in electively delivery in electively induced nulliparous. Obstet Gynecol. 2005;105:698704.

Cite this article as: Bassetty $\mathrm{KC}$, Ahmed RD. F Failed induction of labor (IOL): an overview regarding obstetric outcome and its significance in a health resource poor setting over a period of 11 months. Int J Reprod Contracept Obstet Gynecol 2017;6:3646-50. 